ZOOLOGIA 28 (3): 321-333, June, 2011

doi: $10.1590 /$ S1984-46702011000300006

\title{
The biology and functional morphology of Macoma biota (Bivalvia: Tellinidae: Macominae)
}

\author{
Pedro Ribeiro Piffer¹; Eliane Pintor de Arruda² \& Flávio Dias Passos³
}

\author{
1 Programa de Pós-Graduação em Ecologia, Departamento de Biologia Animal, Instituto de Biologia, Universidade Estadual \\ de Campinas. 13083-970 Campinas, SP, Brazil. Corresponding author. Email: pedropiffer@gmail.com \\ 2 Universidade Federal de São Carlos, Campus Sorocaba. Rodovia João Leme dos Santos, km 110, Itinga, \\ 18052-780 Sorocaba, SP, Brazil. \\ ${ }^{3}$ Departamento de Biologia Animal, Instituto de Biologia, Universidade Estadual de Campinas. Caixa Postal 6109, \\ 13083-970 Campinas, SP, Brasil.
}

\begin{abstract}
Macoma biota Arruda \& Domaneschi, 2005, is a recently described species known only from the intertidal zone of Praia da Cidade, Caraguatatuba Bay, in the state of São Paulo, southeastern Brazil. The main purpose of the present paper is to describe the biology of M. biota, beginning with a detailed analysis of its anatomy and functional morphology and how these attributes are correlated with its habitat and life history. The morphology of the organs in the pallial cavity and their sorting devices indicate that this species has efficient mechanisms to process large amounts of particles that enter this cavity via the inhalant current. $M$. biota can rapidly select the material suitable for ingestion and direct the undesired excess to the rejection mantle tracts. These characteristics along with the siphon's behavior and the digestive tract configuration reveal that this species can be classified primarily as a deposit feeder, like other species of the genus; however, it can also behave as a suspension feeder, depending on the environmental conditions.
\end{abstract}

KEY WORDS. Anatomy; behavior; deposit-feeder; mode of life; Mollusca.

Tellinoidea is one of the largest groups of Bivalvia, and species of this family are conspicuous by their high diversity in tropical and subtropical waters. Tellinoidea are ecologically important in many places, and they frequently constitute food and economic resources for many human coastal populations. All examined species of this family also possess a cruciform muscle near the base of the inhalant siphon, and most species also have a long, unfused siphon (Yonge 1949). Since the study of Yonge (1949), knowledge of the mode of life of tellinoideans has increased, revealing that this family is composed of both deposit and suspension feeding species (e.g., Brafield \& Newell 1961, Pohlo 1969, 1982, Narchi 1972, 1978, Gilbert 1977, Domaneschi 1995, Arruda et al. 2003, Passos \& Domaneschi 2004). The deposit feeders have long and mobile inhalant siphons, which are characteristic of many Tellinidae, whereas the suspension feeders are more phenotypically diverse and culminate in the short and passive siphons present in the Donacidae.

Both deposit and suspension feeding individuals can be found in Tellinidae, even within the same species (BRAFIELD \& Newell 1961, Gilbert 1977). This is the largest tellinoidean group and is composed of two subfamilies, Tellininae and Macominae, distinguished by the presence of lateral hinge teeth in Tellininae and their absence in Macominae. In some places, the diversity of tellinids (and tellinoideans in general) is probably underes- timated because many species have very similar shells that can only be distinguished by accurate morphological examinations, including examination of the soft parts. The Brazilian coast is a location that provides an example of this issue. As a result of a substantial effort by the "Marine benthic biodiversity of São Paulo State" program (BIOTA/FAPESP) to describe the marine diversity in the state of São Paulo, 30 tellinoideans were recorded, including one new species, Macoma biota by Arruda \& Domaneschi, 2005. This species is a large bivalve that can be easily confused with the well-known Macoma constricta (Bruguière, 1792) (ARruda \& Domaneschi 2005).

Because of the high diversity of Tellinidae, the biology of relatively few species is known. Among the 43 reported Brazilian species (Rios 1994, 2009), only three were studied and examined for anatomical details. The Macominae have received the most attention, with the examination of Temnoconcha brasiliana Dall, 1921 (Boss \& KeNK 1964), M. constricta (NARCHI 2003) and M. biota (ARruda \& Domaneschi 2005). NARCHI (2003) studied the relationship between the siphonal organ and the labial palps of the species, and recently, ARRUda \& DomanesCHI (2005) investigated the gross morphology of the soft parts of this species in a comparative study with M. biota. The shells of species of Tellina Linnaeus, 1758, from the western coast of the Atlantic were compared (Boss 1966, TeNóRIo 1984), but no anatomical data were furnished. 
Macominae, which is probably a polyphyletic branch, originated in the Eocene and includes nine recent genera (COAN et al. 2000). In addition to T. brasiliana and Cymatoica orientalis (Dall, 1890), ten species of Macoma have been recorded from Brazilian shores (Tenório et al. 1986, Rios 1994, 2009, ArRudA \& DomANeschi 2005). Data on the life histories of these species are very scarce once $M$. constricta is the only species that has been observed alive (ARRUda et al. 2003). A few other Macominae species have already been investigated, such as Macoma balthica (Linnaeus, 1758), which was analyzed by Brafield \& Newell (1961) and Gilbert (1977), and eight other species, which were investigated by ReID \& ReID (1969). In the latter study, deposit feeding was recorded among some species, while others were characterized as suspension feeders. Another species of Macomona, Blainville, 1814, from Thailand was analyzed by Simone \& WiLKISON (2008).

In the present study, a detailed anatomical investigation of $M$. biota was undertaken to contribute to the knowledge of M. biota biology. These data will help to further distinguish this species from other Macominae species, providing basic information for future studies on the taxonomy and phylogeny of this diverse group. Special attention has been given to the structure and functioning of the pallial organs, as they are directly involved in food capture and therefore define the role that this species plays in the community structure of Brazilian muddy beaches.

\section{MATERIAL AND METHODS}

During low tide, living specimens of $M$. biota were collected manually using a common shovel in the intertidal zone of Praia da Cidade, which is a sheltered beach near downtown Caraguatatuba in the state of São Paulo, Brazil (2337'31.08"S, $\left.45^{\circ} 23^{\prime} 57.38^{\prime \prime} \mathrm{W}\right)$. This is the type locality of this species and the only area in which it is presently known. The physical characteristics of the beach were described by ARRUDA \& DOMANESCHI (2005). The sediment is composed mainly of fine and very fine sand and retains a large amount of silt-clay (mean sediment size: $2.82 \varnothing$ ). The sediment includes $6.64 \%$ organic matter and $8.88 \%$ calcium carbonate, and the interstitial seawater salinity is $34 \% \mathrm{~S}$.

The individuals of M. biota were found in the muddysand substratum near beds of the mytilid Mytella charruana (d'Orbigny, 1842). In the laboratory, living animals were kept in aquaria containing seawater and clean sand at $21^{\circ} \mathrm{C}$ with constant aeration. The specimens were fed powdered fish food that was poured in the surrounding seawater three times a week. Under these conditions, specimens survived for 60 consecutive days. The burrowing and feeding behavior and the position adopted by M. biota within the sediment were observed using small aquaria containing sand immersed in seawater. Anatomical and behavioral studies were conducted with healthy specimens during the first few weeks of confinement in aquaria. After the first month, the specimens began to weaken in re- sponse to the lack of a proper food supply. This affected their behavior and could have interfered with the experiments; therefore, when specimens began to show signs of weakness, they were anesthetized and fixed for further use.

For the morphological study of the organs of the mantle cavity and digestive tract, specimens were anesthetized using a $2.5 \%$ solution of magnesium chloride or menthol crystals, fixed with a $4 \%$ formaldehyde solution and preserved in $70 \%$ alcohol. Living specimens were dissected and observed under a dissecting microscope, and ciliary currents and sorting mechanisms were elucidated using powdered carmine and fine organic and mineral particles. The organs and structures were compared in both preserved and living conditions and drawn using a camera lucida attached to a Zeiss STEMI SV-6 stereomicroscope.

For histological examination, specimens fixed with Bouin's fixative had their shells removed and were then dehydrated in a crescent alcoholic series (70, 80, 95, and 100\%), embedded in paraffin and serially microtomized in 7-10 1/4m thick sections. The sections were stained with hematoxylin and counterstained with either eosin or Mallory's triple stain.

Voucher specimens of this study were deposited in the molluscan collection of the "Museu de Zoologia da Unicamp Prof. Dr. Adão José Cardoso" (lot ZUEC-BIV 2192).

\section{RESULTS}

Macoma biota lives burrowed deep in the sediment, approximately 20 to $40 \mathrm{~cm}$ below the surface (Fig. 1). When removed from the sediment and left lying on the right or left valve, the animal extends its foot antero-ventrally and bends it toward the substratum in an attempt to anchor itself. Once the foot is anchored in the substratum, the anterior and posterior pedal retractor muscles contract, lifting the shell upward to a vertical position. From this position, the animal begins to burrow, assisted by an abrupt shutting of the valves, which expels the water contained in the pallial cavity and displaces the sediment thus opening space for the shell to penetrate. During this process, the siphons remain partially protracted and are not affected by the harsh shutting of the valves because of a small opening in the posterior region of the shell. Specimens measuring $4 \mathrm{~cm}$ long buried themselves in approximately $15 \mathrm{sec}$.

Once fully buried, M. biota assumes a horizontal position, lying on the left shell valve (Fig. 1); at this point, the siphons are protracted beyond the surface of the sediment and re-initiate the intake of food and water. The fact that this species lies on the left valve is corroborated by a small flexure to the right in the posterior region of the shell, exactly where the animal protracts its siphons. In laboratory conditions, certain specimens emerged from the substrate and remained lying on the surface. This tended to occur after a few weeks of confinement in the aquarium, probably resulting from the fact that the animals began to become unhealthy when submitted to conditions that differed from those of their natural environment. 


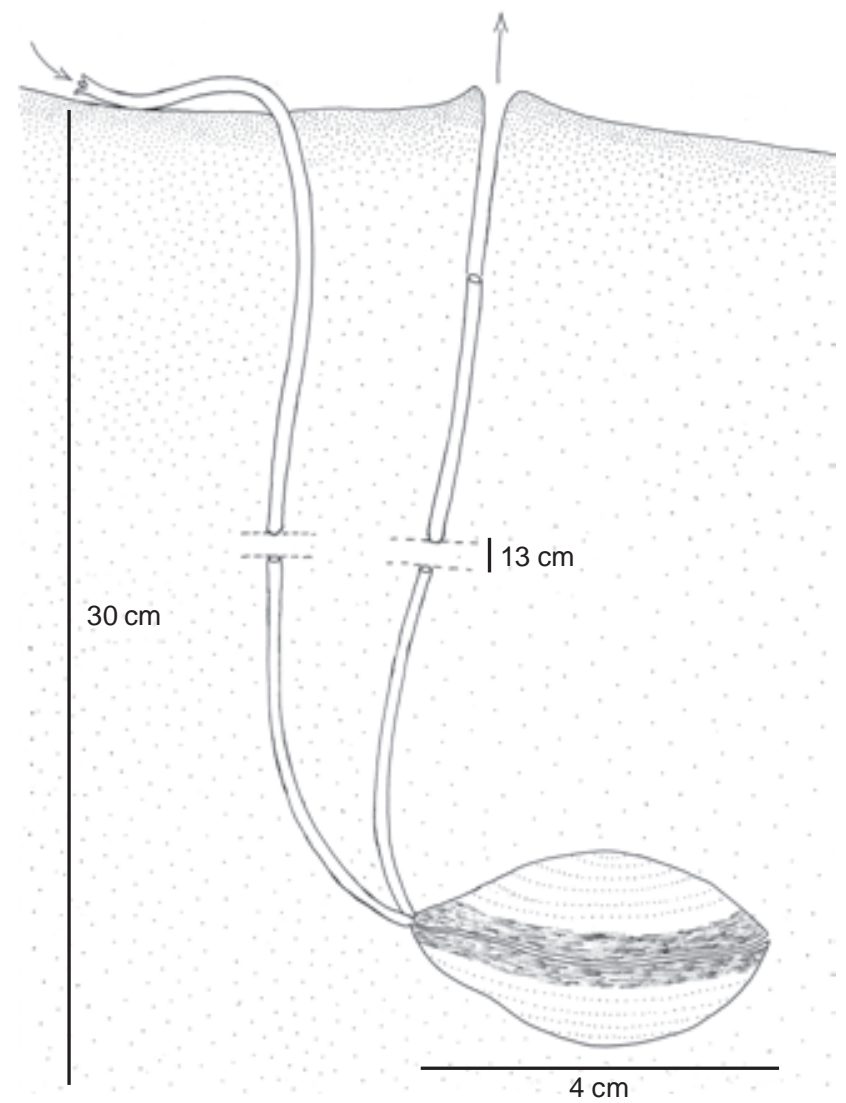

Figure 1. Macoma biota: specimen fully buried in its natural habitat, lying on the left shell valve. The arrows indicate the directions of the inhalant and exhalant currents.

The adductor muscles were unequal in cross section; the anterior muscle was dorso-ventrally elongated, and the posterior muscle was ovate. In addition to the two typical adductor muscles, M. biota possesses an accessory adductor muscle uniting the valves in the ventral-posterior region and serving the same function as the adductors (Fig. 2). This muscle originates from the hypertrophy of the pallial musculature and is located between the anterior and posterior insertions of the cruciform muscle. It leaves an ovate scar in both valves that is united with the pallial line scar at its posterior extremity. At the base of this accessory adductor muscle is the cruciform muscle, which is composed of two muscular bundles, each with its anterior extremity fixed in one valve and its posterior extremity fixed in the opposite valve (Fig. 2). Halfway between the fixation points in the valves, the fibers of each bundle intercalate, crossing each other and then reconstituting the original bundle. The posterior extremity of each bundle penetrates between the mantle lobe tissues and bifurcates into two sub-equal bundles immediately before being affixed to the valve, which leaves two unequal scars. Anteriorly to the bifurcation, each muscu-

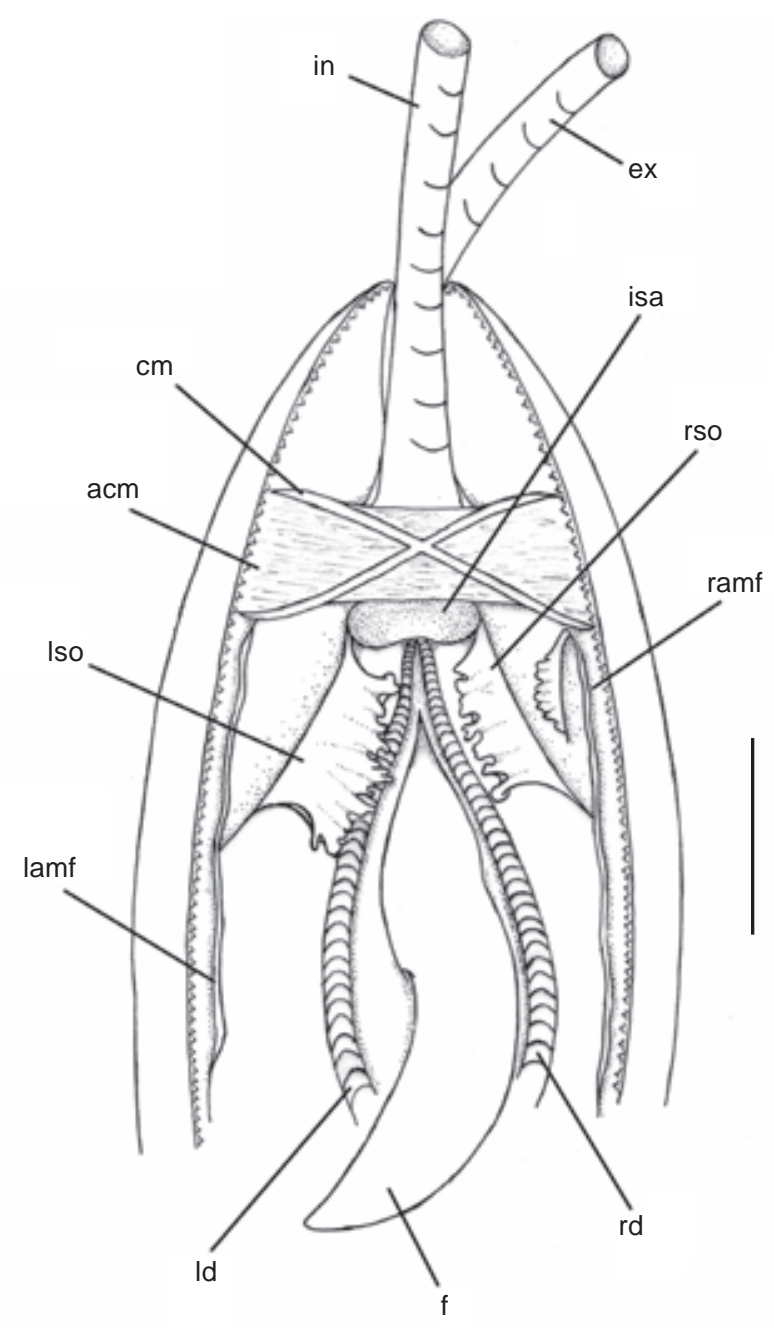

Figure 2. Macoma biota: ventral view representing $3 / 4$ of a specimen with the valves half-open showing the position of the siphonal organs and the accessory adductor and cruciform muscles. (acm) Accessory adductor muscle, (cm) cruciform muscle, (ex) exhalant siphon, (f) foot, (in) inhalant siphon, (isa) inhalant siphon proximal aperture, (lamf) left additional mantle fold, (Id) left inner demibranch, (Iso) left siphonal organ, (ramf) right additional mantle fold, (rd) right inner demibranch, (rso) right siphonal organ. Scale bar: $5 \mathrm{~mm}$.

lar bundle is separated completely by a gap, which communicates with a sensorial organ that is typical of Tellinoidea.

The mantle lobes are thin and translucent, except at their thickened, muscular, three-folded ventral margins. The mantle lobes are completely unattached antero-ventrally, forming an extensive pedal opening. At the posterior end, the opposing inner folds fuse and are involved in siphon formation. At the base of the inhalant siphon, the pallial musculature hypertrophies, originating the accessory adductor muscle and the cruciform muscle. The inner mantle folds are short, translucent 
and barely visible, even in live specimens dissected under a microscope. The middle sensorial fold bears a single row of regularly spaced, short and digitiform tentacles. The outer fold is less developed than the others, and it is very difficult to visualize.

Both mantle lobes present a long and smooth additional fold located dorsally to the inner fold, isolating a waste channel for pseudofeces (Fig. 2). Both additional mantle folds extend posteriorly from the mid-point of the pedal opening up to the vicinity of the cruciform muscle. At this point, the left additional fold ends, and the right fold bends abruptly dorsally and forward, extending anteriorly and increasing in height, with the free edge becoming lobulated and often intensively ramified.

The material that comes in contact with the internal mantle epithelium is quickly conduced ventrally and posteriorly by two very active ciliary currents. The first current collects the material that precipitates close to the anterior adductor muscle and transfers it first to the dorsal surface of the additional mantle fold and then to the base of the inhalant siphon. The second current is dorso-ventrally directed throughout the umbo line; the material precipitated in the anterior and posterior regions of the mantle epithelium converge at this current. The material dragged dorso-ventrally to the siphonal organs is equally concentrated in the proximity of the inhalant siphon base (Fig. 3).

All material removed from the surface of the left mantle lobe is concentrated in the posterior extremity of the left additional mantle fold. In the opposite lobe, the material is concentrated in the interior of the hollow formed by the flexion of the right additional mantle fold (Fig. 3).

A pair of asymmetric siphonal organs is located close to the proximal aperture of the inhalant siphon in both mantle lobes (Fig. 2). The left siphonal organ is more developed than the right, but both are slightly cushion-like at the base and bordered by a thin, plicate sheath at the free apical edge. The left and right siphonal organs of $M$. biota present similar and very active ciliary currents in both surfaces. On the dorsal surface, the cilia drag the material mostly to the anterior margin of the siphonal organ, transferring it to the ventral surface. On the ventral surface, the ciliary currents transfer the particles to the base of the siphonal organ and then posteriorly to a region near the proximal aperture of the inhalant siphon (Fig. 4).

All the material that originated from the rejection currents of the ctenidia, labial palps, visceral mass and mantle epithelium is concentrated close to the proximal aperture of the inhalant siphon and is eliminated as pseudofeces through the inhalant siphon by an abrupt adduction of the valves.

The siphons are formed exclusively by the fusion and hypertrophy of the inner folds of the mantle. These siphons are present in the posterior region of the bivalve and are classified as type A based on the definitions of Yonge $(1948,1982)$. The siphons are long, cylindrical, separated and very active, moving freely and diminishing gradually in diameter in the direction of the tip. The inhalant siphon is longer than the exhalant and, when fully extended, reaches four to five times the shell length. The inhalant aperture is fringed with six simple lobular projections, forming small tentacles that are visible only when it is fully distended. The tentacles are inconspicuous and barely detectable when the animal is fixed or when it contracts the siphons (Fig. 5). The exhalant aperture is more elaborate as a result of the occurrence of six small digitiform tentacles that are intercalated by digitiform papillae (Fig. 5). The siphons are whitish, smooth and thin organs with a segmented appearance caused by the presence of circular and regularly spaced constrictions. The siphon walls present six longitudinal white lines that are regularly spaced and visible due to transparency. These lines correspond to the nerves that end in the interior of the six projections in both apertures. The siphon walls and apertures are sensitive to mechanical stimulation and harsh movements of the water in their proximity, and they respond with local contractions and/or full retraction to the interior of the sediment or shell.

The siphons can be fully retracted to an isolated space external to the pallial cavity, called the siphonal space. When fully retracted, the proximal portions of the siphons remain near the cruciform muscle line. This is in contrast to other tellinids in which the siphons retract further into the anterior region and occupy a considerable part of the pallial cavity. The retraction process is facilitated by the fan-shaped siphon retractor musculature, which is well developed in the Tellinoidea.

In the absence of perturbations, $M$. biota can protract its siphons slowly, exposing the apertures above the sediment surface and remaining like this for long periods of time. The protraction of the siphons is relatively slow and continuous and is a result of the combined actions of the intrinsic musculature and the blood.

The specimens maintained in the aquaria behaved as either deposit feeders or suspension feeders. When they fed on material in suspension, the inhalant siphon remained outside of the substratum, either passively lying on the surface or extended into the water column. When they fed on material deposited in the substratum, the specimens protracted the inhalant siphon well above the surface and bent it in the shape of a hook, putting the aperture in contact with the surface and sucking the material precipitated in the sediment. As a result, large quantities of sediment entered the mantle cavity.

When the exhalant siphon was protracted above the surface of the substratum, it remained passive most of the time. Sporadically, the exhalant siphon performed circular movements to launch feces far from the inhalant aperture. In many instances, the exhalant siphon remained retracted in the interior of the substratum with its aperture located below the surface of the sediment.

The foot is a huge, axe-shaped and very active muscular organ that expands far beyond the antero-ventral margin of 


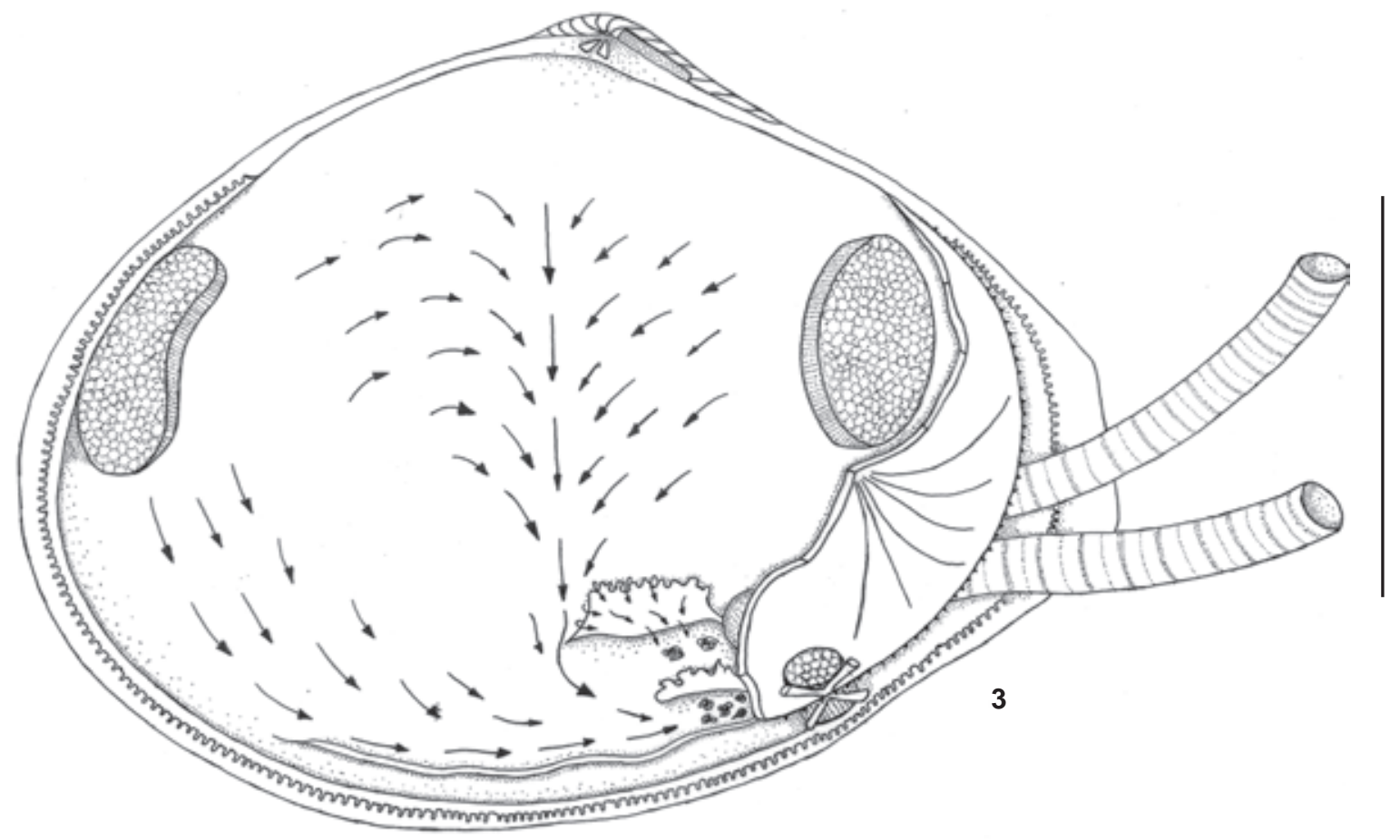

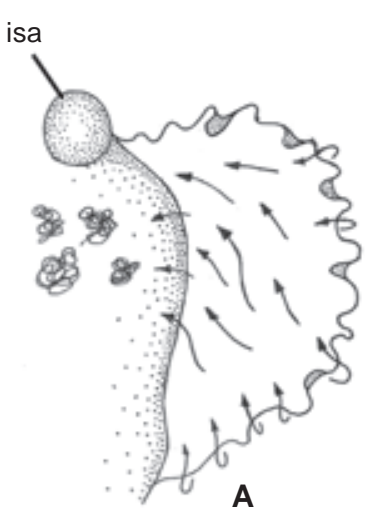

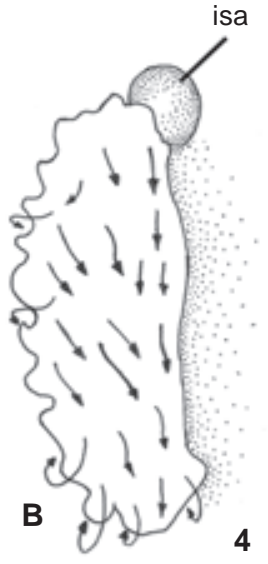

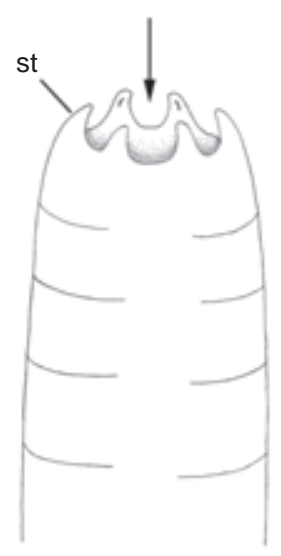

Inhalant

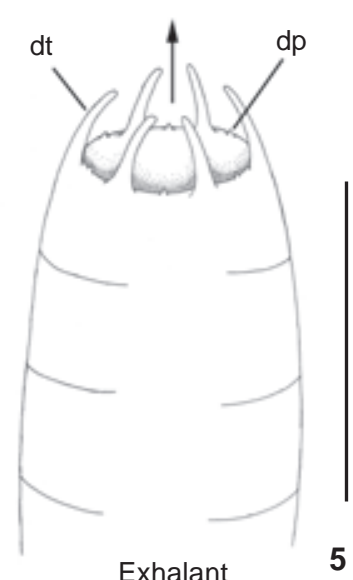

Exhalant
5

Figures 3-5. Macoma biota. (3) Ciliary currents on the inner surface of the right mantle lobe. Observe the accumulation of pseudofeces in the space formed by the additional mantle fold. (4) Ciliary currents on the surface of the left siphonal organ; (A) ventral surface, (B): dorsal surface. (5) distal extremity of the siphons, showing the inhalant aperture with six lobular small tentacles and the exhalant aperture with six small digitiform tentacles, intercalated by digitiform papillae. (dp) Digitiform papillae, (dt) digitiform tentacle, (isa) Inhalant siphon proximal aperture, (st) small tentacle. Scale bars: $3=1.5 \mathrm{~cm}, 4=5.0 \mathrm{~mm}, 5=2.0 \mathrm{~mm}$.

the shell. The proximal portion of the foot remains protected inside the shell and holds the visceral mass.

The intrinsic pedal musculature is composed of two types of muscular bundles: the first is arranged transversely, uniting the epithelium of both sides of the foot, and the second is ar- ranged obliquely in the lateral walls of the foot. The extrinsic pedal musculature is composed of three pairs of bundles that are attached to the shell valves and extend to different regions of the foot. These include one pair of protractor muscles and two pairs of retractor muscles (anterior and posterior) (Fig. 6). 


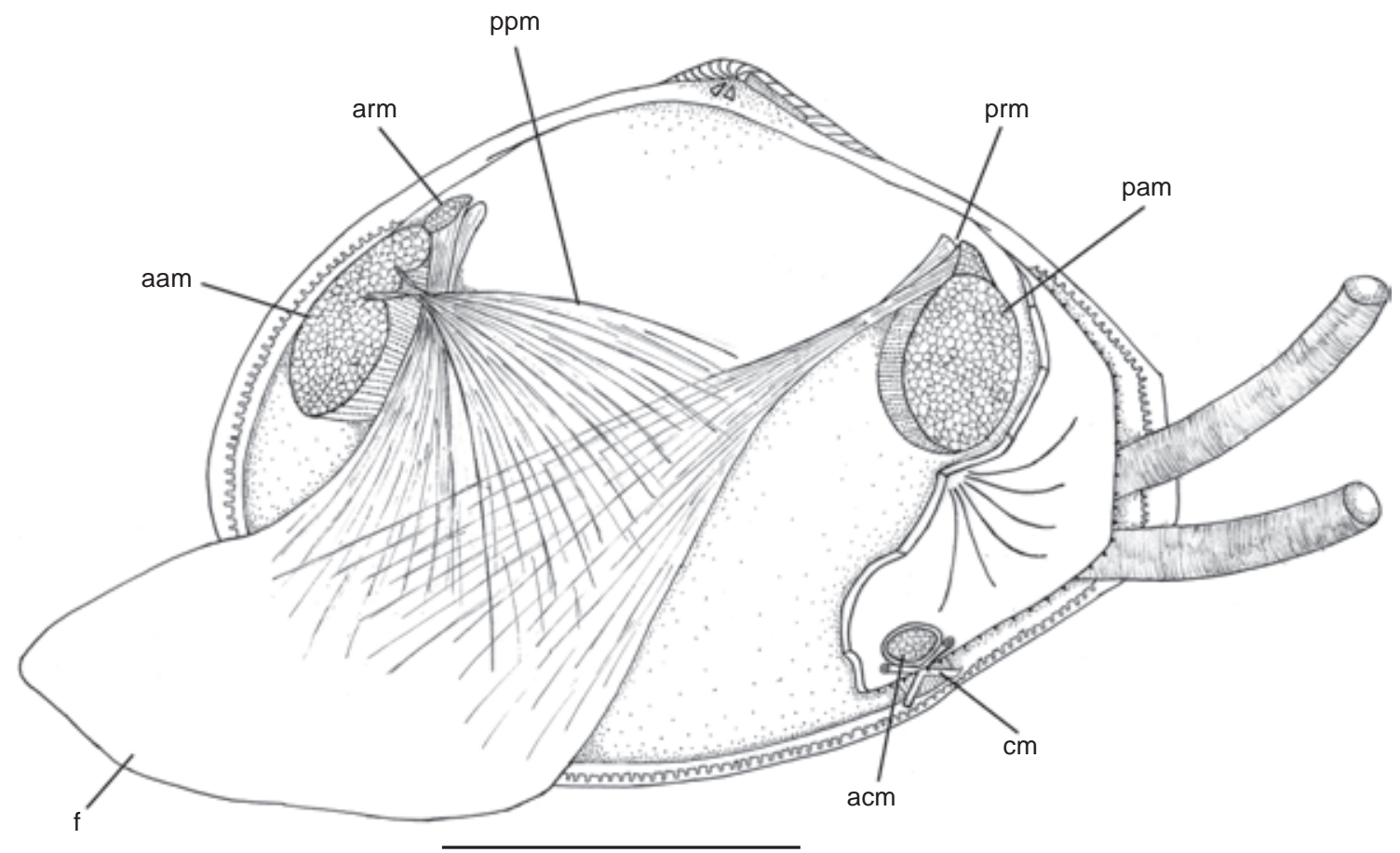

Figure 6. Macoma biota: the arrangement of the musculature. (aam) anterior adductor muscle, (acm) accessory adductor muscle, (arm) anterior pedal retractor muscle, $(\mathrm{cm})$ cruciform muscle, (f) foot, (pam) posterior adductor muscle, (ppm) pedal protractor muscle, (prm) posterior pedal retractor muscle. Scale bar: $1.5 \mathrm{~cm}$.

The insertion of the anterior pedal retractor muscles (arm) is elongated and lies dorsally to the anterior adductor muscle. These muscles form the innermost muscular layers of the foot and extend nearly ventrally. The muscular bundles of the anterior retractor muscles intercross in the middle portion of the sagittal plane of the bivalve. The right bundles cross with those originating from the left and vice versa, forming a thicker region that then separates again and extends ventrally.

The insertion of the posterior pedal retractor muscle (prm) is triangular and lies dorsally to the posterior adductor muscle. These muscles form the middle muscular layer of the foot between the anterior retractor and protractor muscles. The right and left posterior pedal retractor muscles proceed anteriorly, converging in the sagittal plane and fusing just beneath the kidney, thus forming a thick median bundle. At this point, the bundles of fibers intersect and split; the fibers from the right side pass deeply into the left side of the foot and vice versa, irradiating to the whole lateral area of the foot.

The pedal protractor muscles (ppm) on each side of the foot penetrate the anterior adductor muscle transversely, attaching to their respective valves with the anterior adductor muscle fibers. Splitting of the muscular bundles occurs a short distance before the pedal protractors penetrate the anterior adductor to form a thicker ventral portion that concentrates most of the muscular fibers and a thinner dorsal portion that has few muscular fibers. From their insertion on the shell valve, the pedal protractors follow posteriorly and twist abruptly as they enter the foot and then spread in a fan pattern toward all proximal regions of the foot that hold the visceral mass. These muscles form the outermost muscular layer of the foot, and they are external to the posterior retractor.

The foot epithelium presents ciliary activity only on the portion that holds the visceral mass. This activity occurs on the area in contact with the inner demibranchs and labial palps. This ciliary activity is relatively weak, and the material that enters into contact with the epithelium of the visceral mass in this region can be captured by the cilia on the smooth face of the internal labial palp or the demibranchs. When this does not occur, the material is carried ventrally and posteriorly and accumulated in the posterior region of the visceral mass, where it is covered by the inner demibranch (Fig. 7). The material is then agglutinated by mucus, which causes precipitation to the mantle. At the mantle, the material is transferred to the proximal aperture of the inhalant siphon and is eliminated as pseudofeces.

The general configuration of the organs and structures of the pallial complex can be viewed in figure 8 . The ctenidia are complete, eulamellibranch and totally smooth (homorhabidic). The interfilamentar and interlamellar junctions occur regularly in the ctenidia. The inner demibranch is complete, 


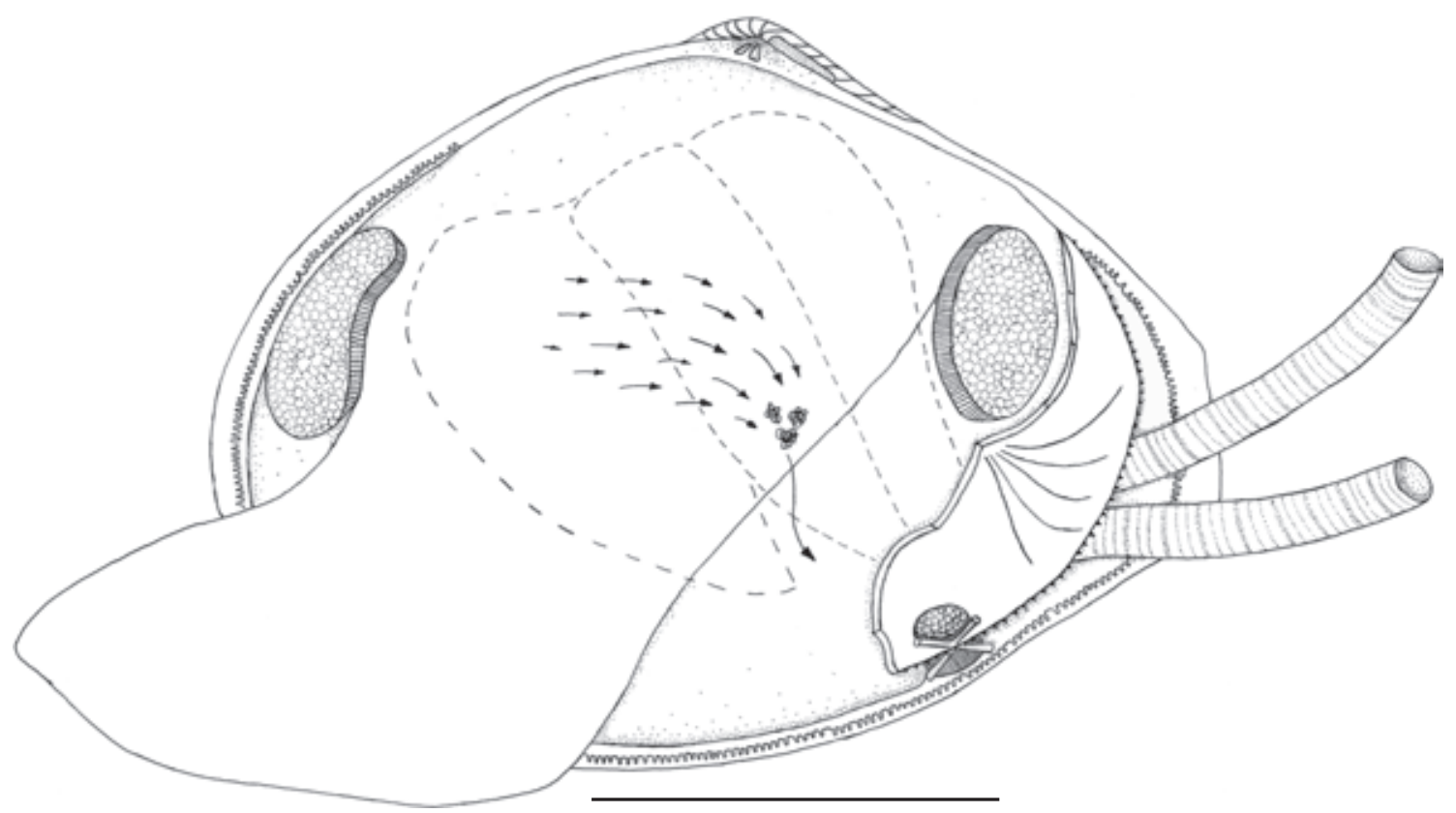

Figure 7. Macoma biota: ciliary currents on the proximal region of the foot's epithelium that holds the visceral mass. The left ctenidium and labial palps were removed and the dashed lines indicates their original position in the live animal. Scale bar: $1.5 \mathrm{~cm}$.

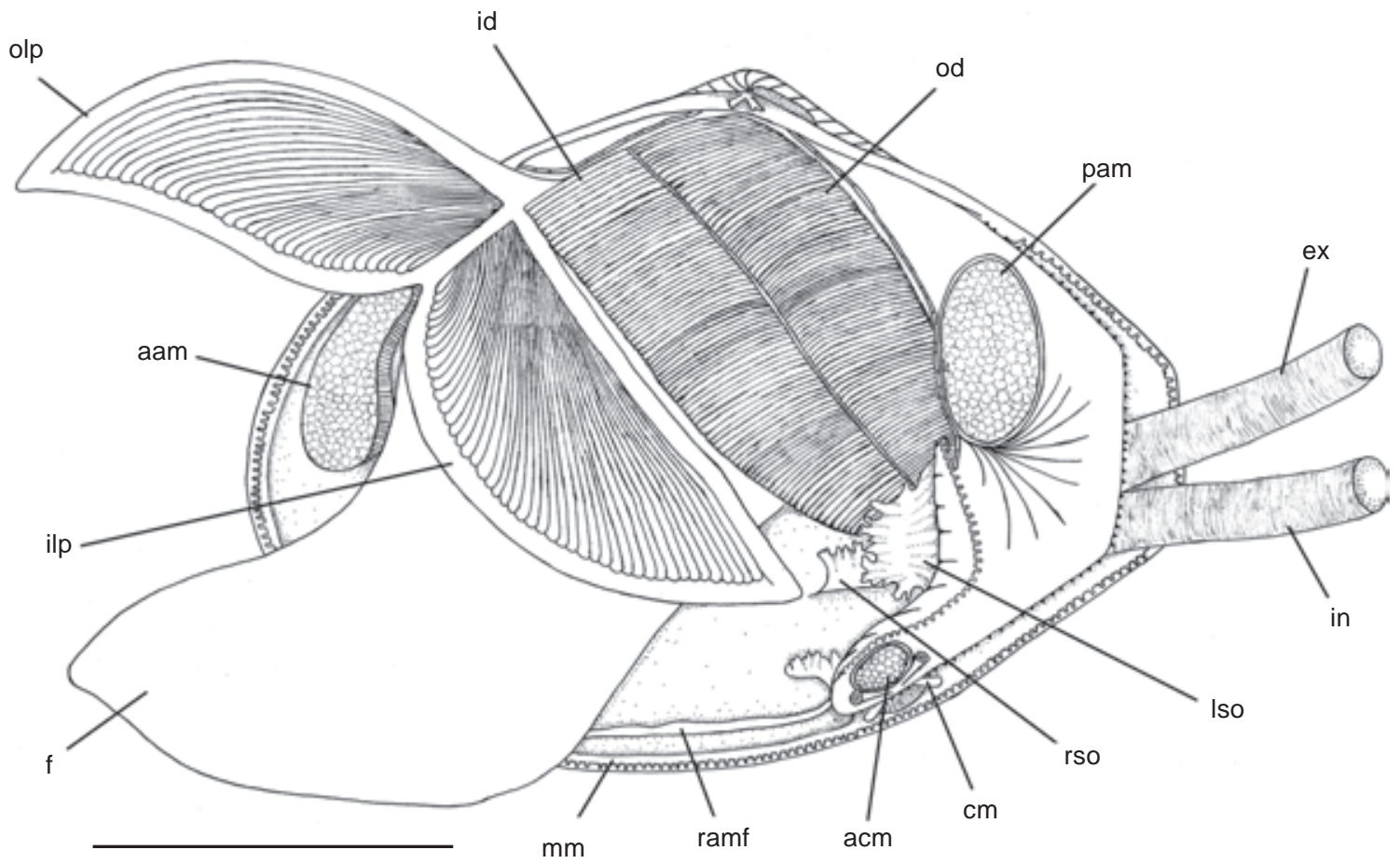

Figure 8. Macoma biota: organs of the pallial cavity viewed from the left side after the removal of the left shell valve and mantle lobe. (aam) anterior adductor muscle, (acm) accessory adductor muscle, (cm) cruciform muscle, (ex) exhalant siphon, (f) foot, (id) inner demibranch, (ilp) inner labial palp, (in) inhalant siphon, (Iso) left siphonal organ, (mm) mantle margin, (od) outer demibranch, (olp) outer labial palp, (pam) posterior adductor muscle, (ramf) right additional mantle fold, (rso) right siphonal organ. Scale bar: $1.5 \mathrm{~cm}$. 
with both ascending and descending lamellae. The outer demibranch is reduced to the single descending upturned lamellae, leaving the inner demibranch uncovered. Both demibranchs have the same length and height (Fig. 9). The inner demibranch has a shallow marginal food groove along its free margin. The ctenidia axis is located diagonally in relation to the antero-posterior axis of the bivalve body, and it extends from the umbonal concavity to the base of the siphons.

The filaments of both demibranchs have frontal, laterofrontal and lateral cilia. The frontal face of the filaments presents a longitudinal band of equally sized frontal cilia, which are followed laterally by the latero-frontal cilia. The latero-frontal cilia are long and rigid, and as their extremities touch and intercalate with the cilia from the adjacent filament, they form a barrier to larger particles brought by the inhalant current, obstructing the entrance of these particles into the interior of demibranch. Bands of lateral cilia occur on the sides of the filaments; their vibration promotes the water flow trough the mantle cavity. The filaments are internally reinforced with chitin developed on the lateral walls. No pro-latero-frontal cilia were detected in M. biota.

The ciliary currents on the ctenidia are represented in figure 9 . The material introduced to the pallial cavity by the inhalant current that then reaches the outer demibranch is conduced to the ctenidia axis, where an oral current of acceptance transfers the smaller particles in a dorso-anterior direction to the distal oral groove, which is formed between the outer labial palp and the demibranchs. Excess and rejected particles are transferred to the descendent lamellae of the inner demibranch. In both lamellae of the inner demibranch, ciliary currents conduct material to the free margin, and the smaller particles are agglutinated in mucus, transferred to the marginal food grove and conducted orally for digestion or for new selection in the labial palps. Larger particles, agglomerates of particles and surplus materials that are in contact with the inner demibranch are discharged from the free margin to the mantle epithelium.

The labial palps are trigonal, large, wide and approximately two-thirds of the shell length. The labial palps and ctenidia have similar lengths, although the labial palps are sometimes slightly longer. The inner labial palps are located between the visceral mass and the ascending lamellae of the inner demibranch, and the outer labial palps are located between the mantle and the descending lamellae of the same demibranch. The association between the ctenidia and the labial palps of M. biota is classified as type III based on the definitions of STASEK (1963) (Fig. 10).

The external surfaces of the labial palps are smooth, and the internal surfaces are highly and conspicuously folded. The folded face has two smooth borders: one is large and dorsal in relation to the folds, and the other is thin and ventral, with a free margin that can be affected by muscular contractions forming simple or highly truncate lobular formations, assuming a fringed aspect (Fig. 10). Histological sections showed that the labial palp folds have a smooth oral face and an aboral face with longitudinal thickenings that give them a wavy aspect (Fig. 11).

Particles that come into contact with the external, smooth face of the labial palps are removed transversely in a dorsal direction and transferred to the broad, dorsal, smooth border on the internal face (Fig. 10). On this border, longitudinal convergent currents concentrate the particles to a specific point that is set back from the distal extremities of the palps, and the particles are then transferred to the folds for selection. Isolated particles from the distal oral groove, the frontal face of the filaments of the anterior region of the inner demibranch, the marginal food groove, and the inner demibranch are also brought to the folded area. Particles agglutinated in a mucus strand that reaches the palps through the distal portion of the oral groove and the marginal food groove go directly to the mouth.

Different ciliary currents on the folded faces of the labial palps (Figs 10 and 11) rigorously select the material to be ingested. A very active current (a) carries isolated particles and agglomerated particles perpendicularly across the crests of the folds, being transferred from fold to fold. This current operates obliquely in an oral direction and markedly in a ventral direction, and it can act either as an acceptance or a rejection current, depending upon the size or total volume of the particles. The fold inclination determines whether the material will be transferred to the proximal oral groove between the palps and then directed to the mouth or transferred to a strong longitudinal rejection current (b) along the ventral, smooth border of the palps. The material on the rejection current is carried to the distal free extremity of the palp and then discharged to the mantle epithelium.

Other ciliary currents occur along the grooves formed between the folds and on the aboral face of these folds, and these currents act as rejection or acceptance mechanisms, respectively. The longitudinal currents (d) on the aboral face of the folds impede the immediate discharge of material, whereas fine particles that precipitate on the floor of the grooves between the folds are carried longitudinally (current " $c$ ") to the rejection tract " $b$ " on the free ventral margin of the palp. The longitudinal current " $\mathrm{d}$ " along the aboral face of each fold acts to re-sort particles, capturing them from current " $a$ " and keeping them on the palp for re-selection. The joint action between currents " $\mathrm{a}$ " and " $\mathrm{d}$ " retains the particles for a longer time in the folded face to allow for gradual selection of particles for ingestion or rejection. This interaction is responsible for the zigzag trajectory that carries the material to the base of the palps, preventing the particles to reach the rejection tract " $\mathrm{b}$ " on the smooth ventral border.

Large, isolated particles or particle agglomerates precipitated in large quantities on the folds are captured by current " $a$ " and are conduced to rejection tract " $b$ " on the free ventral 

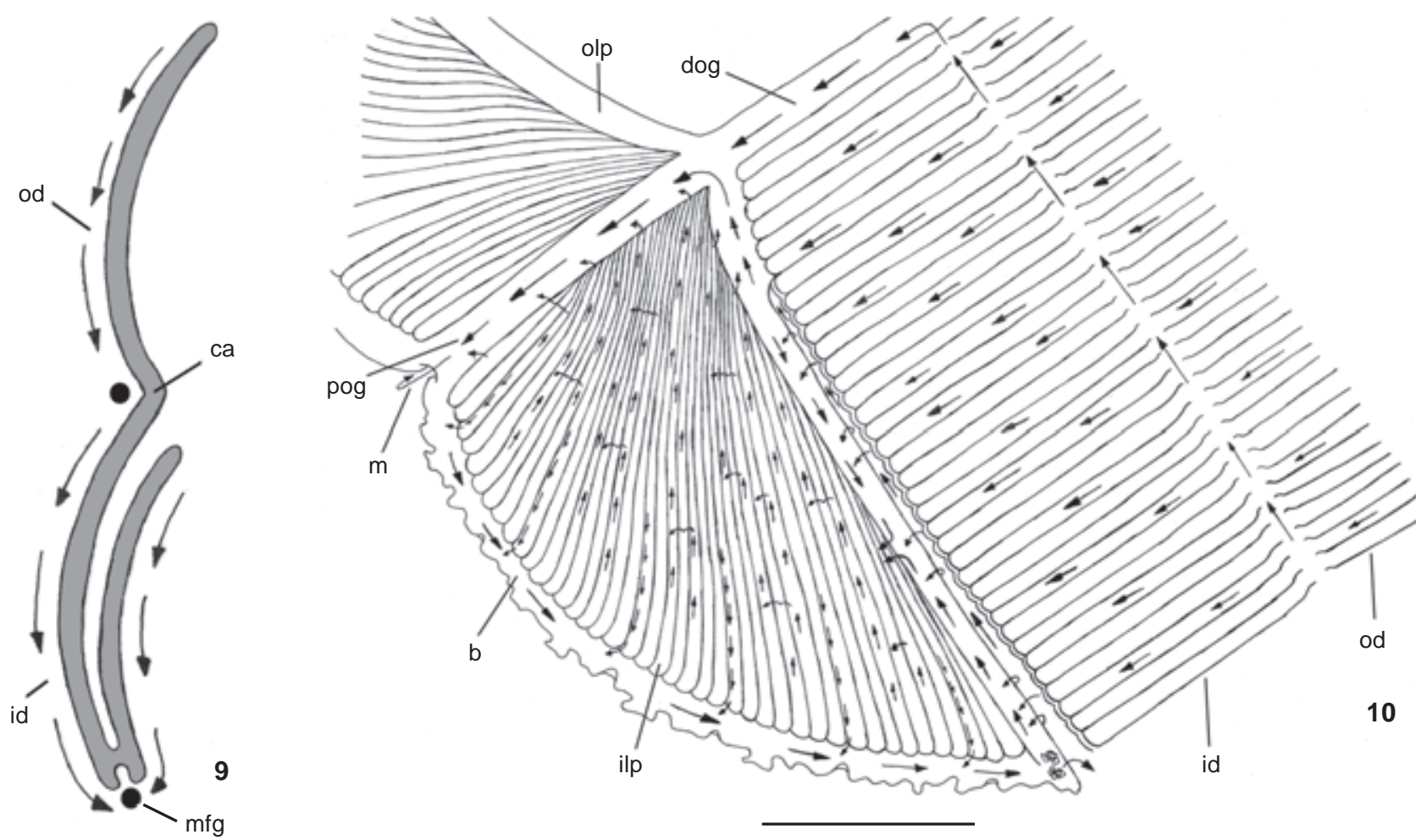

Figures 9-10. Macoma biota. (9) Diagrammatic vertical section through the ctenidium showing its functional organization: arrows ventralward and bullets oralward ciliary currents. (10) Relationship between the left labial palps and inner demibranch, and respective ciliary currents. (b) Rejection current along the ventral smooth border, (ca) ctenidium axis, (dog) distal oral groove, (id) inner demibranch, (ilp) inner labial palp, (m) mouth, (mfg) marginal food groove, (od) outer demibranch, (olp) outer labial palp, (pog) proximal oral groove. Scale bar: $5 \mathrm{~mm}$.

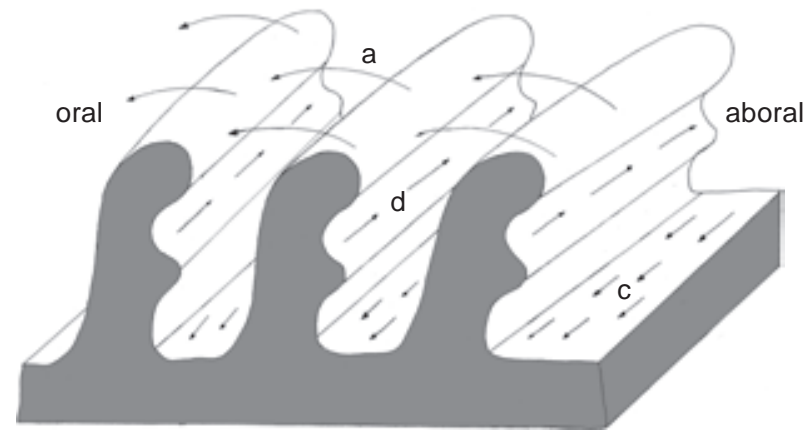

Figure 11. Macoma biota: diagram of the ciliary mechanisms on the folded surface of the labial palp, to show the various ciliary tracts. For lettering (a), (c), (d), see text.

border of the palps. This activity is enhanced when muscular action approaches the fold crests or curls or wraps the organ. By approaching the folds, the bivalve creates a barrier that blocks the penetration of particles in the space between the folds, thus making current "a" act as a rejection current. The curling and wrapping of the labial palps also results in a barrier and facilitates the capture of material by rejection current " $b$ ".

The labial palps can contract severely with consequent wrinkling but without wrapping. This contraction forms four to five folds ("secondary folds") transverse to the longitudinal axis of the organ. These folds are temporary functional formations that speed up the rejection process of large quantities of material by favoring current " $\mathrm{a}$ ", which carries the material quickly to rejection tract " $\mathrm{b}$ ".

Beyond the mouth is the flattened and relatively short esophagus, which extends posteriorly and opens into the stomach dorso-anteriorly (Fig. 12). The stomach is globular, with thin, fragile and semi-translucent walls. From the posterior region of the stomach roof, slightly bending toward the right side, projects the short and digitiform appendix, which is homologous to the posterior caecum. Additionally, the dorsal hood projects from the stomach roof and bends posteriorly. Below the dorsal hood, there is a broad left pouch that opens into the anterior region of the stomach in line with the esophagus opening. The left pouch has two branches: a thinner branch that extends anteriorly and a wider branch that extends posteri- 


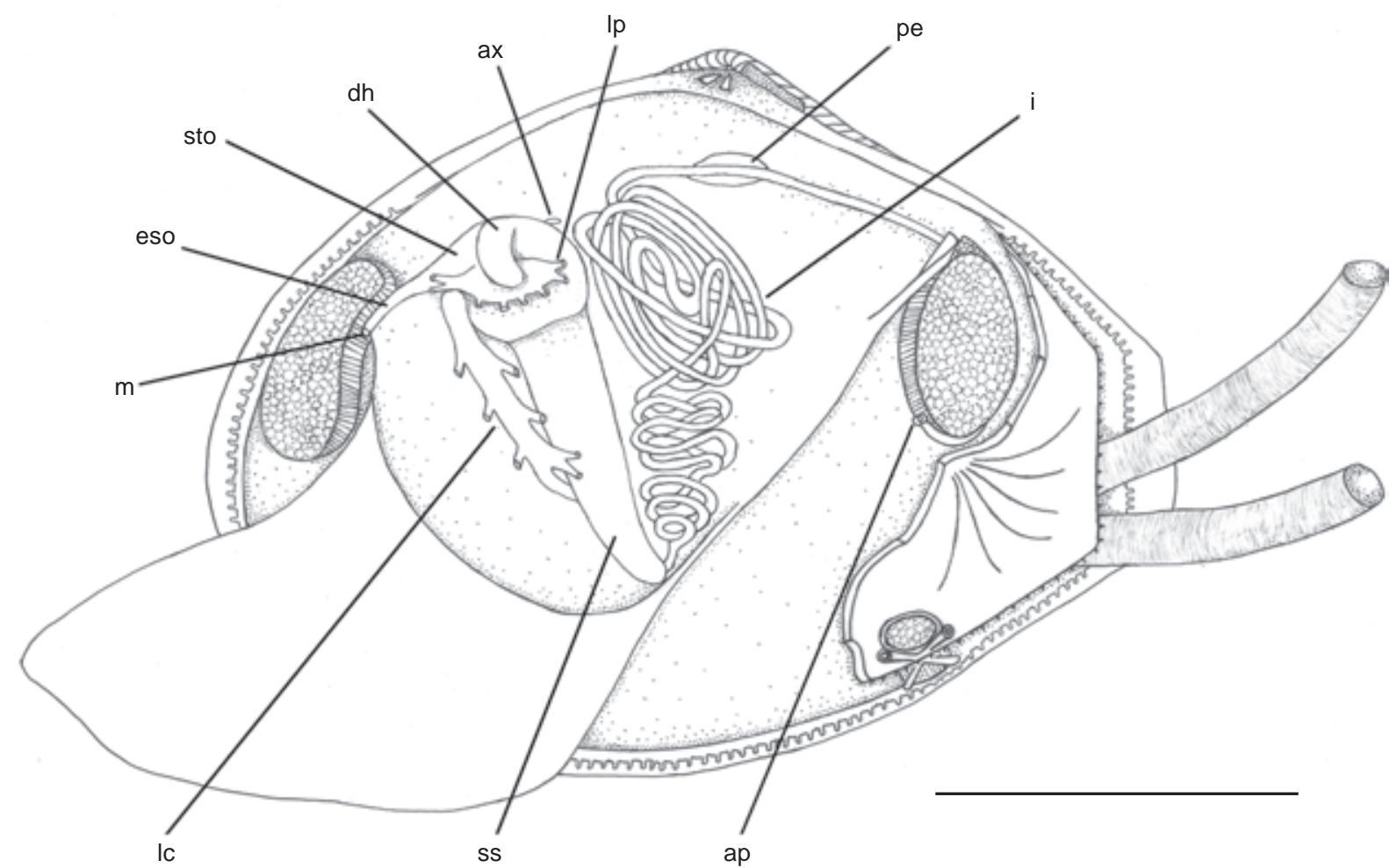

Figure 12. Macoma biota: left side view of a dissected specimen showing the alimentary canal. (ap) Anal papillae, (ax) appendix, (dh) dorsal hood, (eso) esophagus, (i) intestine, (Ic) left caecum, (Ip) lef pouch, (m) mouth, (pe) pericardium, (ss) style-sac, (sto) stomach. Scale bar: $1.5 \mathrm{~cm}$.

orly. The left pouch receives some ducts from the digestive diverticula in the distal extremity of the anterior branch and from all along the free margin of the posterior branch.

The remainder of the ducts that comes from the dense mass of digestive diverticula, which covers the entire front, left and right sides of the stomach and style-sac, opens into the stomach via the right and left caeca. The right caecum is short and highly reduced, and it is located on the right side of the stomach and extends anteriorly. The right caecum receives some ducts from the digestive diverticula mostly on its distal extremity, but some branches also arrive close to the beginning of the caecum. The left caecum opens into the anterior region of the stomach, and it is cylindrical and far more developed than the right caecum. The left caecum receives several ducts from the digestive diverticula and extends ventrally until approximately the middle portion of the style-sac. At that point, the left caecum divides into two portions: one spreads to the left side of the style-sac and the other to the right.

The style-sac and the intestine open together in the postero-ventral region of the stomach floor, separated by the minor and major typhlosoles. The style-sac is conical and extends postero-ventrally. The crystalline style has the shape of a baseball bat, is quite rigid and is always present in both live and fixed specimens. The distal extremity of the crystalline style projects into the stomach, occupying a large amount of internal space in this organ.

The intestine continues from the distal region of the stylesac and is located in a very compact cavity that is well separated from other organs. The intestinal loops and gonads form a very compact mass. The diameter or caliber of the intestine is relatively constant during its entire length, and its walls are extremely elastic and have great powers of distention. The intestine can acquire a diameter almost five times larger than its normal diameter, depending on the quantity of fecal pellets accumulated in its interior. The intestine describes a large number of loops, divided into two sets. In the first set, the intestine describes three circular loops in the horizontal plan, and after that, it assumes a winding aspect, describing three to four more irregular loops in the same plan. In the first set, the loops are very compact and entangled. From the middle portion of its trajectory, the intestine describes a second set of loops, constituted by seven to eight circular loops in a more vertical plan. After that, the intestine reaches the pericardium and goes through the ventricle. After crossing the pericardium, the intestine passes over the dorsal surface of the posterior adductor muscle and ends with the anus, which has two small papillae in its opening. 


\section{DISCUSSION}

Macoma biota demonstrates a series of adaptations that allow it to colonize a habitat with large amounts of suspended sediment. The limited horizontal mobility of individuals that remain burrowed deeply in the substratum for long periods in the same place is related to the mode of life on calm beaches with little surf, which is the only locale where the species has been recorded. The inhalant siphons of $M$. biota do not possess any barriers that could block the entrance of large amounts of sediment in the pallial cavity. However, when the particles reach the pallial cavity, they are quickly selected by the intense ciliary activity of the pallial organs.

According to Yonge (1949), the ctenidia shape of M. biota, with the complete inner demibranch and incomplete outer demibranch, is an adaptation to deal with large amounts of material that enter the pallial cavity. The outer demibranch, which is reduced to a single descending, upturned lamellae, and the inner demibranch form a continuous surface that propitiates a greater efficiency of transport and selection for the sediment that comes in contact with the ctenidia and also contributes to reduce the risk of damaging the organ. The strong currents observed on the marginal food groove and on the ctenidia axis ensure the efficiency of particle transport in the oral direction. The labial palps, which are more developed than the ctenidia, play a major role in the selection of the particles that are directed to the mouth. The presence of labial palps that are more developed than the ctenidia is also observed in species that live in muddy habitats where the material that enters the pallial cavity is very fine (Yonge 1949).

The large ciliary activity of the labial palps and the formation of a "cone of rejection" that occurs when these curl or wrap up also indicates that these animals deal with a large inflow of deposited material that requires efficient selection mechanisms to sort between the particles to be ingested and the ones to be rejected. Moreover, the large ciliary activity of the labial palps of M. biota is related to the re-selection of material brought by the inhalant current.

The presence of an additional fold in each mantle lobe, forming a ventral waste channel that was named by KelLogG (1915), is characteristic of many deposit feeding tellinoids (Yonge 1949) and also some suspension feeding veneroids (NARCHI \& Di DARIO 2002). The waste channel isolates unwanted sediment from the strong inhalant current and can drag these materials back to the pallial cavity organs. The ventral channel was described for Abra alba (Wood, 1801) and Scrobicularia plana (da Costa, 1778) by Yonge (1949), T. brasiliana by Boss \& KenK (1964) and M. constricta by NARCHI (2003). ReID \& ReID (1969) also described the presence of a waste channel in Macoma brota Dall, 1916, M. calcarea (Gmelin, 1791), M. elimata Dunnil \& Coan, 1968, M. incongrua (Martens, 1865), M. inquinata (Deshayes, 1855), M. secta (Conrad, 1837), M. lipara Dall, 1916, and M. nasuta (Conrad, 1837). In M. biota, the additional mantle fold forms a waste channel slightly different from those described by Kellogg (1915). In M. biota, the rejected material is carried dorsally in relation to the folds, not ventrally, and it accumulates close to the proximal aperture of the inhalant siphon in the interior of the space formed by the flexion of the right additional mantle fold. At this location, it is also isolated from the inhalant current as a result of the development of the right additional mantle fold.

Macoma biota possesses a pair of siphonal organs, described for the first time by Boss \& KenK (1964) in T. brasiliana and by NARCHI (2003) in M. constricta. In contrast with $T$. brasiliana and $M$. constricta, which have unique left siphonal organs, M. biota has a paired structure, and the left organ is more developed than the right. According to NARCHI (2003), $M$. constricta has a strongly wavy sheath in the distal extremity of the outer left labial palp that maintains an intimate functional relationship with the unilateral left siphonal organ. The particles rejected by the left labial palp are first passed to the plicate wall of the free margin of the siphonal organ and later passed to the aperture of the inhalant siphon. With the inflow of water from the inhalant current, this material can be conveyed to the ctenidia to be processed again. NARCHI (2003) concluded that the presence of ciliary currents conveying particles to the aperture of the inhalant opening shows that the bivalve can re-sort material rejected by the labial palps. The presence of an always-moving plicate wall around the cushion-like base of the unilateral left siphonal organ also suggests that this organ is sensory (NARCHI 2003).

In M. biota, this sheath is absent; however, the ciliary currents on the paired siphonal organ convey particles from the labial palps and mantle cavity to the aperture of the inhalant opening, similar to M. constricta. However, we did not observe the inflow of water from the inhalant current conveying particles back to the ctenidia. The particles caught by the paired siphonal organs are conveyed to the posterior extremity of the waste channel and eliminated as pseudofeces. The paired siphonal organs agglutinate large quantities of particles that are eliminated by labial palps and ctenidia on the mantle cavity. The organs probably handle with larger amounts of material than the unique left siphonal organ of $M$. constricta. The sensory function of the siphonal organ could not be confirmed in this study.

The siphonal organ may be present in other species. REID \& ReID (1969) studied the feeding processes of Macoma species and named a structure present on the right mantle lobe in a similar position to the siphonal organ the "mantle fold". SimONE \& Wilkinson (2008) described an organ in the left mantle lobe called the "pseudogill" in Moerella cf. nitens (Deshayes, 1854), Pinguitellina cf. pinguis (Hanley, 1844), Elpidollina sp., Tellinides timorensis (Lamarck, 1818) and Macomona species. According the authors, the pseudogill is located in an equivalent place to the siphonal organ, and "the functional name is based on similar structures present in that region in other bivalves, e.g., lucinids" (SimONE \& WiLIINSON 2008). The structures known as mantle gills 
of lucinids are not located in the same region as the siphonal organ. The mantle gills of lucinids are located between the anterior adductor muscle and the ventral mantle margin (TAYLOR \& GLOVER 2000), whereas the siphonal organs are present on each side of the proximal opening of the inhalant siphon. The functional position of the mantle gills and the siphonal organs is similar: both are at the entrance of the incoming water current. However, the abundant blood supply of the lucinid mantle gills is evidence that these structures have a respiratory function (TAYLOR \& GLOVER 2000). Although there has been no direct physiological study, there is no evidence of blood vessels associated with the siphonal organs. The functional anatomy observed in this study demonstrates that the siphonal organs increase the superficial area of the mantle, agglutinate a large quantity of particles eliminated by the pallial organs and convey this material to the waste channel.

The presence of a single, short, stout accessory adductor muscle that attaches ventrally to both shell valves had been observed only in M. biota until now. This muscle has the same function as the paired adductor muscles, which is the adduction of the valves.

Macoma biota has a very long and curly intestine, which is similar to the majority of deposit feeders. Yonge (1949) suggested that this morphology is related to the need to accumulate and consolidate great quantities of particles originating from the stomach. According to PoHLO (1973, 1982), certain anatomical and functional characteristics are indicative of a species' feeding habit. Macoma biota presents several characteristics that classify it as a deposit-feeder, such as long and separate siphons, the presence of a waste channel, an upturned outer demibranch, and an inhalant opening without tentacles. Features related to the suspension-feeding habit such as large ctenidia related to the labial palps, a non-reflected outer demibranch, the absence of a waste channel, and an inhalant opening provided with many elaborate straining tentacles are absent in M. biota. Based on observations of the behavior of the inhalant siphon, Brafield \& Newell (1961) and Pohlo (1969) determined that species of Macoma might feed on both deposited and suspended material. Individuals feed on deposits when the tide is out, but when the tide is in, they seem to behave as suspension feeders. A behavior analysis of the siphons of $M$. biota specimens kept in aquaria indicates that the species is both a deposit feeder and a suspension feeder, with the first mode being predominant. However, in the present study, the specimens of Macoma biota where kept always immersed in seawater, and the occurrence of these two feeding strategies cannot be attributed to tidal variation.

However, these morphological and behavioral characteristics do not define the feeding habit of bivalves. Some species, such as Semele purpurascens (Gmelin, 1791) and Semele proficua (Pulteney, 1799), have a mosaic of characteristics of both suspension and deposit-feeders (Domaneschi 1995). These species were considered by PонLо (1982) as an intermediate step in the evolution of Tellinoidea that originated from a selective suspension-feeding ancestor. Donax Linnaeus, 1758, species may be representative of this plesiomorphic condition, and depositfeeders like Macoma species are representative of an apomorphic condition.

The morphological and behavioral characteristics presented in this study indicate that $M$. biota has efficient mechanisms to deal with great quantities of particles that enter the pallial cavity through the inhalant current. These animals are able to quickly select material for ingestion and direct the unwanted remainder to the rejection mantle tracts. The study of the functional anatomy of M. biota demonstrates that the siphonal organs are able to increase the superficial area of the mantle and agglutinate large amounts of particles. Unlike other previously studied Tellinidae species, M. biota possesses a pair of siphonal organs and also has an accessory adductor muscle. The species can be classified primarily as a deposit feeder, similar to other species of the genus, but individuals can also behave as suspension feeders.

\section{ACKNOWLEDGEMENTS}

We wish to express our sincere thanks and pay our tribute to Osmar Domaneschi, the professor who educated and guided the authors' through most of their academic formation. Dr. Osmar was also the first author supervisor during most of the present study and contributed much for the accomplishment of this. We are particularly grateful to Sônia G.B.C. Lopes, who assumed the first author supervision after Osmar decease, and our colleagues at the Laboratório de Malacologia, IB-USP, for their help and encouragement in the laboratory studies; and to the Departamento de Zoologia, IB-USP, CEBIMar-USP and Departamento de Biologia Animal, IB-UNICAMP for the logistical support provided. This research was supported by scholarships granted by the Fundação de Amparo a Pesquisa do Estado de São Paulo - FAPESP (Proc. 06/57637-7) and by Coordenação de Aperfeiçoamento de Pessoal de Nível Superior - CAPES through the Programa de Pós-Graduação em Ecologia, IB-UNICAMP.

\section{LITERATURE CITED}

Arruda, E.P. \& O. Domaneschi. 2005. New species of Macoma (Bivalvia: Tellinoidea: Tellinidae) from southeastern Brazil, and with description of its gross anatomy. Zootaxa 1012: 13-22.

Arruda, E.P.; O. Domaneschi \& A.C.Z. Amaral. 2003. Mollusc feeding guilds on sandy beaches in São Paulo State, Brazil. Marine Biology 143: 691-701. doi: 10.1007/s00227-003-1103-y.

Boss, K.J. 1966. The subfamily Tellininae in the Western Atlantic. Johnsonia 4 (45-47): 217-364.

Boss, K.J. \& V.C. Kenk. 1964. Anatomy and Relationships of Temnoconcha brasiliana. Occasional Papers on Mollusks 2 (30): 325-343. 
Brafield, A.E. \& G.E. Newell. 1961. The behavior of Macoma balthica (L.). Journal of Marine Biological Association of the United Kingdom 41: 81-87.

CoAn, E.V.; P.V. Scott \& F.R. Bernard. 2000. Bivalvia Seashells of Western North America. Marine Bivalve Molluscks from Artic Alaska to Baja California. Santa Barbara Museum of Natural History, 764p.

Domaneschi, O. 1995. A comparative study of the functional morphology of Semele purpuracens (Gmelin, 1791) and Semele proficua (Pulteney, 1799) (Bivalvia: Semelidae). The Veliger 38 (4): 323-342.

Gilbert, M.A. 1977. The behavior and functional morphology of deposit feeding in Macoma balthica (Linné, 1758) in New England. Journal of Molluscan Studies 43: 18-27.

KellogG, J.L. 1915. Cilliary mechanisms of Lamellibranchs. Journal of Morphology 26: 625-701.

NARCHI, W. 1972. On the biology of Iphigenia brasiliensis Lamarck, 1818 (Bivalvia, Donacidae). Proccedings of the Malacological Society of London 40 (2): 79-91.

NARCHI, W. 1978. Functional anatomy of Donax hanleyanus Philippi 1874 (donacidae-Bivalvia). Boletim de Zoologia da Universidade de São Paulo 3: 121-142.

NARCHI, W. 2003. The relationship between the unilateral siphonal organ and labial palps of Macoma constricta (Bruguière, 1792) (BIvalvia: Tellinidae). Journal of Molluscan Studies 69: 359-363.

NARCHI, W. \& F. Di Dario. 2002. The anatomy and functional morphology of Tivela ventricosa (Gray, 1838) (Bivalvia: Veneridae). The Nautilus 116 (1): 13-24.

Passos, F.D. \& O. Domaneschi. 2004. Biologia e anatomia funcional de Donax gemmula Morrison (Bivalvia, Donacidae) do litoral de Sao Paulo. Brasil. Revista Brasileira de Zoologia 21 (4): 1017-1032.

PoHLo, R.H. 1969. Confusion concerning deposit feeding in the Tellinacea. Proceedings of the Malacological Society of London 38: 361-364.

PoHLo, R.H. 1973. Feeding and associated functional morphology in Tagelus californianus and Florimetis obesa (Bivalvia: Tellinacea). Malacologia 12 (1): 1-11.
PoHLo, R.H. 1982. Evolution of the Tellinacea (Bivalvia). Journal of Molluscan Studies 48 (3): 245-256.

Reid, R.G.B. \& A. Reid. 1969. Feeding of members of the genus Macoma (Mollusca: Bivalvia). Canadian Journal of Zoology 47 (4): 649-657.

Rios, E.C. 1994. Seashells of Brasil. Rio Grande, Museu Oceanográfico Prof. E.C. Rios, Fundação Universidade do Rio Grande, $2^{\text {nd }}$ ed., $368 \mathrm{p}$.

Rios, E.C. 2009. Compendium of Brazilian Sea Shells. Rio Grande, Editora Evangraf, 668p.

Simone, L.R. L. \& S. WiLKInSON. 2008. Comparative morphological study of some Tellinidae from Thailand (Bivalvia: Tellinoidea). The Raffles Bulletin of Zoology, Suplement 18: 151-190.

STASEK, C.R. 1963. Synopsis and discussion of the association of ctenidia and labial palps in the bivalved Mollusca. The Veliger 6 (2): 91-97.

Taylor, J.D. \& E.A. Glover. 2000. Functional anatomy, chemosymbiosis and evolution of the Lucinidae, p. 207225. In: E.M. Harper; J.D. Taylor \& J.A. Cramer (Eds). The Evolutionary Biology of the Bivalvia. London, Geological Society London, Special Publication 177.

TenóRio, D.O. 1984. O gênero Tellina Linnaeus, 1758 (Mollusca, Bivalvia) na plataforma continental brasileira. Trabalhos Oceanográficos, Universidade Federal de Pernambuco 8: 7-138.

TenóRIo, D.O.; R.L.S. Mello \& O.C. Silva. 1986. O gênero Macoma Leach, 1819 (Bivalvia Tellinidae) na plataforma continental brasileira. Caderno Ômega da Universidade Federal Rural de Pernambuco, Série Ciências Aquáticas, 2: 7-39.

Yonge, C.M. 1948. Formation of siphons in Lamellibranchia. Nature 161: 198-199.

Yonge, C.M. 1949. On the structure and adaptation of the Tellinacea, deposit-feeding Eulamellibranchia. Philosophical Transactions of the Royal Society of London, Series B, Biological Sciences 234 (609): 29-76.

Yonge, C.M. 1982. Mantle margins with a revision of the siphonal types in the Bivalvia. Journal of Molluscan Studies 48 (1): 102-103.

Submitted: 01.IX.2010; Accepted: 14.V.2011.

Editorial responsibility: Rosana M. da Rocha 